\title{
Development of A Particle Swarm Optimization- Backpropagation Artificial Neural Network Model And Effects of Age And Gender On Pharmacokinetics Study of Omeprazole Enteric-Coated Tablets In Chinese Population
}

\section{Yichao Xu}

Center of Clinical Pharmacology, the Second Affiliated Hospital of Zhejiang University, School of Medicine, Hangzhou, Zhejiang

\section{Jinliang Chen}

Center of Clinical Pharmacology, the Second Affiliated Hospital of Zhejiang University, School of Medicine, Hangzhou, Zhejiang

\section{Dandan Yang}

Center of Clinical Pharmacology, the Second Affiliated Hospital of Zhejiang University, School of Medicine, Hangzhou, Zhejiang

Yin Hu

Center of Clinical Pharmacology, the Second Affiliated Hospital of Zhejiang University, School of Medicine, Hangzhou, Zhejiang

\section{Bo Jiang}

Center of Clinical Pharmacology, the Second Affiliated Hospital of Zhejiang University, School of Medicine, Hangzhou, Zhejiang

\section{Zourong Ruan}

Center of Clinical Pharmacology, the Second Affiliated Hospital of Zhejiang University, School of Medicine, Hangzhou, Zhejiang

\section{Honggang Lou ( $\square$ louhg@zju.edu.cn )}

Center of Clinical Pharmacology, the Second Affiliated Hospital of Zhejiang University, School of Medicine, Hangzhou, Zhejiang

\section{Research Article}

Keywords: Plasma concentration, pharmacokinetics study, Chinese population, omeprazole, PSO-BPANN

Posted Date: May 25th, 2021

DOI: https://doi.org/10.21203/rs.3.rs-272374/v1

License: (c) (i) This work is licensed under a Creative Commons Attribution 4.0 International License. Read Full License 


\section{Abstract}

Background: The effects of age and gender were explored on pharmacokinetics study of omeprazole enteric-coated tablets in Chinese population and a plasma concentration prediction model was developed. All the data (demographic characteristics and results of clinical laboratory tests) were collected from healthy Chinese subjects in pharmacokinetics study using $20 \mathrm{mg}$ omeprazole enteric-coated tablets. A noncompartmental method was used to calculate pharmacokinetic parameters, and 47 subjects were divided into two groups based on the calculation of the median age. Pharmacokinetic data from the low-age and high-age groups or male and female groups were compared by Student t-test. After a total of 12 variables were reconstruct and convert into independent or irrelative variables by principal component analysis, particle swarm optimization (PSO) was used to construct a backpropagation artificial neural network (BPANN) model.

Result: The model was fully validated and used to predict the plasma concentration in Chinese population. It was noticed that the $C_{\text {max }}, A C_{0-t}, A U C_{0-\infty}$ and $t_{1 / 2}$ values have significant differences when omeprazole was administered by low-age groups or high-age groups while there were slight or no significant differences of pharmacokinetic data were found between male and female subjects. The PSO-BPANN model was fully validated and there was 0.000355 for MSE, 0.000133 for the magnitude of the gradient, 50 for the number of validation checks. The correlation coefficient of training, validation, test groups were $0.949,0.903$ and 0.874 .

Conclusion: It is necessary to pay attention to the age and gender effects on omeprazole and PSO-BPANN model could be used to predict omeprazole concentration in Chinese subjects to minimize the associated morbidity and mortality with peptic ulcer.

\section{Introduction}

Peptic ulcer is a kind of disease with a significant morbidity and mortality in the worldwide ${ }^{[1]}$. Untimely treatment may lead the results of abdominal pain, gastrointestinal bleeding and gastric perforation ${ }^{[2,3]}$. Omeprazole is a kind of Proton pump inhibitors which is widely used to minimize the associated morbidity and mortality of peptic ulcer $[4,5]$. It is usually made into oral enteric-coated granules which can be absorbed from the small intestine within 3-6 hours science omeprazole is an acid-labile compound ${ }^{[6]}$. In China, omeprazole enteric-coated capsules (AstraZeneca Pharmaceutical Co Ltd) were approved for marketing in 2013 by National Medical Products Administration. However, the original AstraZeneca omeprazole enteric-coated tablets had not submitted an import or production registration application yet. Therefore, there is no systematic study on the pharmacokinetics study of omeprazole enteric-coated tablets in Chinese population.

Large inter-individual variations of omeprazole plasma concentrations were found in several studies ${ }^{[7-9]}$. There are many pharmacokinetic studies have been conducted to analyze the relationship between omeprazole level and its influencing factors, such as gender, age, weight and food, however, the results seem controversial due to the limitation of sample size or the defects in experimental design, especially in Chinese population. In addition, it is necessary to construct a plasma concentration prediction model of omeprazole for its responsible and safe use.

In this paper, a pharmacokinetics study of omeprazole enteric-coated tablets was and the effects of age and gender were explored in Chinese population. What's more, a backpropagation artificial neural network (BPANN) model was developed to predict the plasma concentration of omeprazole. 


\section{Methods}

\subsection{Subjects}

The study data was collected from 47 Chinese healthy subjects in 2017 at the Second Affiliated Hospital of Zhejiang University, School of Medicine (Hangzhou, Zhejiang, China). Male and female volunteers who aged from 18 to 45 years with a body mass index between 19 and $26 \mathrm{~kg} \cdot \mathrm{m}^{-2}$ were enrolled. The inclusion criteria were as follows: (1) there were no clinically relevant abnormalities identified by subjects' medical history, physical examination, clinical laboratory tests, vital signs, chest x-ray, and 12-lead ECG. (2) There were no smoke, drug or alcohol abuse allowed by subjects. (3) There were no breastfeeding, pregnant or childbearing potential of female subjects during the study. Subjects were excluded as follows: (1) there was any positive blood screen for HIV or hepatitis or any positive urine drug screen. (2) There was any hospital admission or major surgery, any donation of blood or acute loss of blood or any participation in other clinical trials within 3 months preceding the studies. (3) There was any heavy tea or coffee drinkers of more than $1 \mathrm{~L}$ /day. (4) There was any history of allergies to the study medicines or related substances.

\subsection{Study Design and Safety Assessment}

The study in was registered in ChicTR, the registration numbers were CTR20170876 and the full date of registration was 04/AUG/2017.A single dose of 20mg omeprazole tablet (AstraZeneca Pharmaceutical Co Ltd. Britain) was administered with $240 \mathrm{~mL}$ of water after an overnight fast. A high calorie meal was given within 30 minutes before drug administration and water was forbidden 1 hour before and after drug administration. Blood samples $(2 \mathrm{~mL}$ each) were collected in K2EDTA anticoagulant tubes at predose and $0.5,1,1.5,2,2.5,3,3.5,4,4.5,5,6,7,8,10,12$ hours postdose. The blood samples were centrifuged at $3000 \mathrm{~g}$ and stored at $-80^{\circ} \mathrm{C}$ until analysis. A validated liquid chromatography tandem mass spectrometry (LC-MS/MS) method was used to determine the plasma concentrations of Omeprazole by SHANGHAI XIHUA SCIENTIFIC CO., Ltd

For all studies, safety assessments included vital sign, 12-lead ECG, physical examinations, and clinical tests. Adverse events were evaluated with regard to their seriousness, intensity, time course, outcome, and relationship to the study drug.

\subsection{Pharmacokinetic Statistical Analysis}

Pharmacokinetic analysis was performed by WinNonlin software (Version 6.4, Pharsight Corporation, Mountain View, California), and a noncompartmental method was used to calculate pharmacokinetic parameters. 47 subjects were divided into low-age group (<= 26years old, 24 subjects) and high-age group (> 26years old, 23 subjects) based on the calculation of the median age. Pharmacokinetic data from the low-age and high-age groups or male and female groups were compared by Student t-test.

\subsection{PCA and PSO-BPANN modeling}

All the data of 47 Chinese subjects of demographic characteristics as well as routine biochemical and hematological investigations were collected. A total of 12 variables were reconstruct and convert into independent or irrelative variables by Principal component analysis (PCA), which can lower the data dimension and maintain the most original variable information. Main calculation procedures of PCA are as follows: (1) the data of Chinese subjects collected was carried out on standardized processing. (2) The characteristic value and feature vector of 
the correlation coefficient matrix $\mathrm{R}$ were calculated to make up new indicator variables. (3) The mprincipal components were chosen and the information contribution rate and accumulated contribution rate were calculated.

Particle Swarm Optimization (PSO), presented by Eberhart and Kennedy in 1995, was a heuristic and evolutionary algorithm which inspired by the behavior of birds to locate desirable positions in a given area through cooperation and competition ${ }^{[10]}$. Some entities, called particles, were scattered in the search space in the PSO. The position of each particle represents a possible solution and each solution is the way that in the search of a position in a space, particles change the flying distance and directions via changing the speed. Each particle remembers its optimal position $p_{i D}$ in the searching history in the iteration process. All the optimal positions of all particles is the global optimal position $p_{g D}{ }^{[11]}$. The equation and parameter of particle movement are as follows:

$$
\begin{aligned}
& V_{i D}^{j+1}=\omega V_{i D}^{j}+c_{1} r_{1}\left(p_{i D}^{j}-x_{i D}^{j}\right)+c_{2} r_{2}\left(p_{g D}^{j}-x_{i D}^{j}\right) \\
& x_{i D}^{j+1}=x_{i D}^{j}+V_{i D}^{j+1}
\end{aligned}
$$

Where $i, j, D$ stand for the particle, the current iteration amount and the particle dimension, respectively. ${ }^{j}{ }_{i D}^{j}$ and $V_{i D}^{j}$ are the velocity and position in the $j$ iteration. Non-negative constant $c_{7}$ and $c_{2}$ are the learning factor, which determines the effects of $p_{i D}$ and $p_{g D}$ on the new velocity. $r_{7}$ and $r_{2}$ are the pseudo random amount evenly distributed in the interval $[0,1]$. $\omega$ is the inertia weight, adjusting the searching ability in the solution domain ${ }^{[12,13]}$.

BPANN is a kind of machine learning technology which minimized the error between the network outputs and the desired outputs, adjusted the weights and biases by a small amount at a time through a gradient-based procedure ${ }^{[14,15]}$. The BPANN comprises two procedures: a forward stage where the input signals moved forward through the network and a backward stage where the error is propagated backward from the output layer to the input layer. The error is calculated in the output layer and the parameters is updated for the direction in which the performance function most rapidly decreases ${ }^{[16]}$.

Although the BPANN algorithm is widely used, it might become stuck at the local minimum if the initial weights and biases are far from the optimal values that can give the global optimal solutions ${ }^{[17]}$. Several metaheuristic optimization algorithms, such as PSO, genetic algorithm, and harmony search algorithm were combined with BPANN to overcome this shortcoming ${ }^{[17-19]}$. In this study, PSO had been chosen to improve the performance of BPANN due to its simplicity and wide applicability. Through the global search ability of the PSO algorithm, the initial weights and biases of the BPANN were obtained and the true global optimization and performance improvement were found. The overall calculation process was shown in Fig. 1.

\section{Results}

\subsection{Subject Characteristics}

A total of 47 subjects met the protocol criteria and were enrolled in the study. The characteristics of all subjects, the low-age and high-age groups and male and female groups are summarized in Table 1. 
Table 1

The characteristics of all subjects, the low-age and high-age groups and male and female groups

\begin{tabular}{|c|c|c|c|c|c|}
\hline Characteristics & All subjects & Male group & Female group & $\begin{array}{l}\text { Low-age } \\
\text { group }\end{array}$ & $\begin{array}{l}\text { High-age } \\
\text { group }\end{array}$ \\
\hline Gender(male/female) & $(23 / 24)$ & $(23 / 0)$ & $(0 / 24)$ & $(13 / 11)$ & $(10 / 13)$ \\
\hline Age(years) & $\begin{array}{l}28.6 \pm 6.61 \\
(20.0,42.0)\end{array}$ & $\begin{array}{l}27.6 \pm 6.13 \\
(21.0,42.0)\end{array}$ & $\begin{array}{l}29.2 \pm 6.95 \\
(20.0,42.0)\end{array}$ & $\begin{array}{l}23.3 \pm 1.79 \\
(20.0,26.0)\end{array}$ & $\begin{array}{l}34.3 \pm 4.68 \\
(28.0,42.0)\end{array}$ \\
\hline $\begin{array}{l}\text { Body mass index } \\
\left(\mathrm{kg} \cdot \mathrm{cm}^{-2}\right)\end{array}$ & $\begin{array}{l}27.2 \pm 1.79 \\
(19.2,25.3)\end{array}$ & $\begin{array}{l}22.1 \pm 1.89 \\
(19.2,25.2)\end{array}$ & $\begin{array}{l}21.4 \pm 1.68 \\
(19.3,25.3)\end{array}$ & $\begin{array}{l}21.4 \pm 1.96 \\
(19.2,24.6)\end{array}$ & $\begin{array}{l}22.2 \pm 1.55 \\
(19.3,25.3)\end{array}$ \\
\hline $\begin{array}{l}\text { Hemoglobin count } \\
\left(\mathrm{g} \cdot \mathrm{L}^{-1}\right)\end{array}$ & $\begin{array}{l}141 \pm 14.3 \\
(117,172)\end{array}$ & $\begin{array}{l}153 \pm 7.78 \\
(139,172)\end{array}$ & $\begin{array}{l}130 \pm 9.04 \\
(117,149)\end{array}$ & $\begin{array}{l}142 \pm 13.6 \\
(117,161)\end{array}$ & $\begin{array}{l}140 \pm 15.5 \\
(117,172)\end{array}$ \\
\hline $\begin{array}{l}\text { Red blood cell count } \\
\left(10^{12} \cdot L^{-1}\right)\end{array}$ & $\begin{array}{l}4.69 \pm 0.44 \\
(3.77,5.52)\end{array}$ & $\begin{array}{l}4.98 \pm 0.28 \\
(4.36,5.43)\end{array}$ & $\begin{array}{l}4.43 \pm 0.37 \\
(3.77,5.52)\end{array}$ & $\begin{array}{l}4.79 \pm 0.40 \\
(3.85,5.52)\end{array}$ & $\begin{array}{l}4.59 \pm 0.47 \\
(3.77,5.43)\end{array}$ \\
\hline $\begin{array}{l}\text { White blood cell count } \\
\left(10^{9} \cdot \mathrm{L}^{-1}\right)\end{array}$ & $\begin{array}{l}5.84 \pm 1.23 \\
(4.20,9.10)\end{array}$ & $\begin{array}{l}6.00 \pm 1.17 \\
(4.40,8.80)\end{array}$ & $\begin{array}{l}5.70 \pm 1.32 \\
(4.20,9.10)\end{array}$ & $\begin{array}{l}5.73 \pm 1.38 \\
(4.20,9.10)\end{array}$ & $\begin{array}{l}5.93 \pm 1.11 \\
(4.20,7.90)\end{array}$ \\
\hline $\begin{array}{l}\text { Blood platelet count } \\
\left(10^{9} \cdot \mathrm{L}^{-1}\right)\end{array}$ & $\begin{array}{l}223 \pm 52.9 \\
(114,361)\end{array}$ & $\begin{array}{l}216 \pm 49.3 \\
(114,307)\end{array}$ & $\begin{array}{l}231 \pm 57.4 \\
(142,361)\end{array}$ & $\begin{array}{l}215 \pm 50.2 \\
(148,361)\end{array}$ & $\begin{array}{l}231 \pm 56.6 \\
(114,320)\end{array}$ \\
\hline $\begin{array}{l}\text { Alanine } \\
\text { aminotransferase } \\
\left(\mathrm{U} \cdot \mathrm{L}^{-1}\right)\end{array}$ & $\begin{array}{l}18.7 \pm 3.37 \\
(13.0,28.0)\end{array}$ & $\begin{array}{l}19.0 \pm 3.38 \\
(14.0,26.0)\end{array}$ & $\begin{array}{l}18.6 \pm 3.46 \\
(13.0,28.0)\end{array}$ & $\begin{array}{l}18.8 \pm 2.57 \\
(14.0,25.0)\end{array}$ & $\begin{array}{l}18.7 \pm 4.11 \\
(13.0,28.0)\end{array}$ \\
\hline $\begin{array}{l}\text { Aspartate } \\
\text { aminotransferase } \\
\left(U \cdot L^{-1}\right)\end{array}$ & $\begin{array}{l}14.7 \pm 6.89 \\
(6.00,38.0)\end{array}$ & $\begin{array}{l}17.5 \pm 7.25 \\
(8.00,38.0)\end{array}$ & $\begin{array}{l}11.9 \pm 5.50 \\
(6.00,28.0)\end{array}$ & $\begin{array}{l}12.4 \pm 5.02 \\
(6.00,25.0)\end{array}$ & $\begin{array}{l}14.1 \pm 7.87 \\
(7.00,38.0)\end{array}$ \\
\hline $\begin{array}{l}\text { Blood urea nitrogen } \\
\left(\mathrm{mmol} \cdot \mathrm{L}^{-1}\right)\end{array}$ & $\begin{array}{l}4.14 \pm 1.05 \\
(1.30,7.00)\end{array}$ & $\begin{array}{l}4.60 \pm 0.94 \\
(3.10,7.00)\end{array}$ & $\begin{array}{l}3.69 \pm 0.99 \\
(1.30,5.80)\end{array}$ & $\begin{array}{l}4.12 \pm 0.97 \\
(2.50,5.80)\end{array}$ & $\begin{array}{l}4.17 \pm 1.17 \\
(1.30,7.00)\end{array}$ \\
\hline $\begin{array}{l}\text { Serum creatinine } \\
\left(\mu \mathrm{mol} \cdot \mathrm{L}^{-1}\right)\end{array}$ & $\begin{array}{l}61.9 \pm 12.7 \\
(39.0,89.0)\end{array}$ & $\begin{array}{l}72.3 \pm 8.66 \\
(54.0,89.0)\end{array}$ & $\begin{array}{l}52.5 \pm 5.80 \\
(41.0,61.0)\end{array}$ & $\begin{array}{l}65.1 \pm 12.7 \\
(46.0,89.0)\end{array}$ & $\begin{array}{l}58.9 \pm 12.5 \\
(39.0,79.0)\end{array}$ \\
\hline
\end{tabular}

\subsection{Pharmacokinetics}

The area under the concentration-time curve from dose to last measurable concentration $\left(\mathrm{AUC}_{0}-\mathrm{t}\right)$, the area under the concentration-time curve from dose to infinity $\left(\mathrm{AUC}_{0-\infty}\right)$, the maximum plasma concentration $\left(\mathrm{C}_{\text {max }}\right)$, the time from dose to $C_{\max }\left(T_{\max }\right)$ and the half-life of terminal elimination $\left(t_{1 / 2}\right)$ were calculated. The results of pharmacokinetic parameter of all subjects, the low-age and high-age groups and male and female groups are summarized in Table 2. 
Table 2

The pharmacokinetics parameters of all subjects, the low-age and high-age groups and male and female groups

\begin{tabular}{|c|c|c|c|c|c|}
\hline $\begin{array}{l}\text { Pharmacokinetics } \\
\text { Parameters }\end{array}$ & All subjects & Male group & Female group & Low-age group & $\begin{array}{l}\text { High-age } \\
\text { group }\end{array}$ \\
\hline $\begin{array}{l}\mathrm{AUC}_{0-\mathrm{t}}\left(\mathrm{ng} \cdot \mathrm{h} \cdot \mathrm{mL}^{-}\right. \\
\left.{ }^{1}\right)\end{array}$ & $980 \pm 1121$ & $1067 \pm 1232$ & $715 \pm 1000$ & $1262 \pm 1410$ & $496 \pm 486$ \\
\hline $\begin{array}{l}\mathrm{AUC}_{0-\infty}\left(\mathrm{ng} \cdot \mathrm{h} \cdot \mathrm{mL}^{-}\right. \\
\left.{ }^{1}\right)\end{array}$ & $1063 \pm 1264$ & $1144 \pm 1384$ & $782 \pm 1138$ & $1393 \pm 1598$ & $506 \pm 499$ \\
\hline $\mathrm{C}_{\max }\left(\mathrm{ng} \cdot \mathrm{mL}^{-1}\right)$ & $379 \pm 297$ & $425 \pm 341$ & $283 \pm 234$ & $435 \pm 330$ & $266 \pm 234$ \\
\hline $\mathrm{T}_{\max }(\mathrm{h})$ & $4.50(1.00,8.00)$ & $4.00(1.00,5.50)$ & $4.50(1.50,8.00)$ & $4.50(1.50,8.00)$ & $4.50(1.00,6.00)$ \\
\hline$t_{1 / 2}(h)$ & $1.25 \pm 0.64$ & $1.27 \pm 0.71$ & $1.14 \pm 0.59$ & $1.44 \pm 0.81$ & $0.97 \pm 0.27$ \\
\hline
\end{tabular}

$\mathrm{AUC}_{0-\mathrm{t}}:$ Area under the concentration-time curve from dose to last measurable concentration;

$\mathrm{AUC}_{0-\infty}:$ Area under the concentration-time curve from dose to infinity;

$C_{\text {max }}$ : Peak concentration; $T_{\text {max }}$ : Time from dose to $C_{\text {max }} ; t_{1 / 2}$ : Half-life of terminal elimination.

Data are shown as Mean \pm SD except for $T_{\max }$ which are shown as median (range).

\subsection{Effects of Age and Gender}

The effects of age and gender were compared by Student t-test in SPSS Statistics 19 and the results was shown in Table 3. It was noticed that the $\mathrm{C}_{\mathrm{max}}, \mathrm{AUC}_{0-\mathrm{t}}, \mathrm{AUC}_{0-\infty}$ and $\mathrm{t}_{1 / 2}$ values have significant differences when omeprazole was administered by low-age groups or high-age groups (shown in Fig. 2). However, there were slight or no significant differences of pharmacokinetic data were found between male and female subjects. 
Table 3

The effect of pharmacokinetic parameters of Age and Gender in healthy Chinese subjects

\begin{tabular}{|lll|}
\hline Pharmacokinetics & Age & Gender \\
Parameters $P$ & $<.05(.049)$ & .103 \\
\hline $\mathrm{C}_{\text {max }}\left(\mathrm{ng} \cdot \mathrm{mL}^{-1}\right)$ & .921 & .210 \\
\hline $\mathrm{T}_{\text {max }}(\mathrm{h})$ & $<.05(.017)$ & .287 \\
\hline $\mathrm{AUC}_{0-\mathrm{t}}\left(\mathrm{ng} \cdot \mathrm{h} \cdot \mathrm{mL}^{-1}\right)$ & $<.05(.014)$ & .233 \\
\hline $\mathrm{AUC}_{0-\infty}\left(\mathrm{ng} \cdot \mathrm{h} \cdot \mathrm{mL}^{-1}\right)$ & $<.05(.011)$ & \\
\hline $\mathrm{t}_{1 / 2}(\mathrm{~h})$ & & \\
\hline $\mathrm{AUC}_{0-\mathrm{t}}:$ Area under the concentration-time curve from dose to last measurable concentration; & \\
\hline $\mathrm{AUC}_{0-\infty}:$ Area under the concentration-time curve from dose to infinity; & \\
\hline $\mathrm{C}_{\mathrm{max}}:$ Peak concentration; $\mathrm{T}_{\text {max }}$ : Time from dose to $\mathrm{C}_{\text {max }} ; \mathrm{t}_{1 / 2}:$ Half-life of terminal elimination. \\
\hline
\end{tabular}

\subsection{PCA Result}

The PCA results of 12 variables collected form Chinese healthy subjects were shown in Table 4. We can learn from that the largest 7 characteristic values in the matrix are 3.693,2.252, 1.220, 1.184, 1.000, 0.869, 0.659, all of which are over 0 , and the comprehensive information contribution rate is $90.648 \%$. We can infer that the 7 principal components have basically maintained the original information of all indicators, which can fully reflect the changing trend. So, it is feasible and valid that we choose the 7 principal components to replace the original 12 indicators. 
Table 4

Characteristic values, contribution rate and accumulated contribution rate of PCA.

\begin{tabular}{|llll|}
\hline Variable & Characteristic value & Contribution rate & Accumulated contribution rate \\
\hline x1 & 3.693 & 30.774 & 30.774 \\
\hline x3 & 2.252 & 18.771 & 49.545 \\
\hline x4 & 1.220 & 10.165 & 59.710 \\
\hline x5 & 1.184 & 9.869 & 69.579 \\
\hline x6 & 1.000 & 8.333 & 77.912 \\
\hline x7 & 0.869 & 7.242 & 85.154 \\
\hline x8 & 0.659 & 5.494 & 90.648 \\
\hline x9 & 0.281 & 2.946 & 93.594 \\
\hline x10 & 0.242 & 2.341 & 95.935 \\
\hline x11 & 0.155 & 2.018 & 97.952 \\
\hline x12 & 0.090 & 1.296 & 99.248 \\
\hline
\end{tabular}

\subsection{PSO-BPANN Result}

According to the result of PCA, the final established BPANN model consisted of one input layer with 7 neurons, 1 hidden layer with 13 nodes, and 1 output layer with one node (plasma concentration of omeprazole). MATLAB2020a was used as the processor. All the data (847 data points) collected were randomly divided into a training group (70\%, 591 data points), a validation group (15\%, 128 data points) and a test group (15\%, 128 data points) which involved in none process of modeling. In order to eliminate the effects of input variables, Mapminmax function is used to normalize the sample input data into [-1, 1]. PSO was used to optimize the initial weight and threshold to acquire the optimal parameter and the parameters of PSO were set as follows: population size 50 , evolutionary generation 100 , acceleration factor $c_{1}=c_{2}=1.49445$, intervals of particle position and velocity $[-5,5]$ and $[-1,1]$, respectively. Many hyperparameters were used to train the net where the number of training iterations was set to 1000 , the network performance target was $10^{-7}$ and the learning rate was 0.001 . The transfer function for the hidden layer was "logsig", and that for the output layer was "purelin". The Levenberg-Marquardt optimization method "trainlm" was the training function, and "leanngdm" was the threshold learning function. After the model was trained, the performance of the network was evaluated by following four metrics: the MSE, magnitude of the gradient, number of validation checks, and correlation coefficient. The results indicate good performance: 0.000355 for MSE, 0.000133 for the magnitude of the gradient, 50 for the number of validation checks. The correlation coefficient of training and validation were shown in Fig. $\mathbf{3}$.

\subsection{Application and MIV Result}

The constructed PSO-BPANN model was used to predict the plasma concentration of omeprazole in the test group. The results of predict values compared with measured values were shown in Fig. $\mathbf{4}$ and the correlation coefficient was calculated. The data collected from predicted and measured values were analyzed with paired-samples t test 
(shown in Table 5). All the results of correlation coefficient $(R=0.874)$ and paired-samples t test $(P>0.05)$ show good fitness of PSO-BPANN model.

Table 5

The result of paired-samples $t$ test of predicted and measured values

\begin{tabular}{|lllll|}
\hline & Mean Value & Standard Error of Mean & $\mathbf{t}$ & $\mathbf{P}$ \\
\hline Predicted values & 105 & 19.7 & 1.352 & .179 \\
\cline { 1 - 5 } & & & & \\
\hline
\end{tabular}

The mean impact value (MIV) is an indicator which represents the magnitude of the effect of the input value on the output value. The calculation process of MIVs is as follows: (1) New training samples are formed by increased and decreased $10 \%$ of each input variable values. (2) New training samples are incorporated into the PSO-BPANNs respectively and the two results are subtracted and divided by the number of observations. (3) The sign of the MIV results represent the positive and negative correlation between the variable and the result, and the absolute values of the MIV results represent the importance of the variables. The results of MIVs were shown in Table 6

Table 6

The value of the mean impact value (MIV) of 12 variables

\begin{tabular}{|llll|}
\hline Covariate & Mean effect value & Covariate & Mean effect value \\
\hline Body mass index & 95.13 & White blood cell count & -18.83 \\
\hline Blood urea nitrogen & 31.10 & Hemoglobin count & -20.52 \\
\hline Red blood cell count & 25.19 & Aspartate aminotransferase & -31.49 \\
\hline Alanine aminotransferase & 25.11 & Serum creatinine & -105.55 \\
\hline Blood platelet count & 18.22 & Gender & -127.56 \\
\hline Time & 5.19 & Age & -150.14 \\
\hline
\end{tabular}

\section{Discussion}

In this study, we compared the effects of age and gender on the plasma concentration of omeprazole in Chinese population. At the same time, PCA and PSO-BPANN algorithms were used to predict the blood concentration of omeprazole for the first time.

To our knowledge, the effects of age and gender and the pharmacokinetics parameters of omeprazole entericcoated tablets were explored for the first time among Chinese population. As age and gender were usually considered to be key factors which could alter the pharmacokinetic profiles of the drugs, leading to variation in systemic exposure. We introduced the effects of them into omeprazole pharmacokinetics study in healthy subjects. The results showed the $\mathrm{C}_{\max }$ reduced by $38.8 \%$ in high-age group compared to those found in low-age group. Meanwhile, the mean systemic exposure was observed to be $60.7 \%$ decreased (average of $\mathrm{AUC}_{0-\mathrm{t}}$ ) in high-age group. In our study, the effect of age were found obvious $(P<.05)$ in Chinese population and might be contribute to the lower metabolic capacity in the high-age group. In addition, although there was no obvious different $(P<.05)$ found between male and female in our study, the reduction extents of $\mathrm{C}_{\max }$ and $\mathrm{AUC}_{0-\mathrm{t}}$ were $33.4 \%$ and $33.0 \%$ in female group, compared with male group. It is necessary to understand of age and gender effects on omeprazole, 
which might be lead to better management of patients with peptic ulcer and minimize the associated morbidity and mortality.

BPANN is widely used during our pharmacokinetic research and plasma concentration prediction. In previous research, we used to predict the plasma concentration and pharmacokinetic parameters of four bioequivalence studies of rosuvastatin calcium tablets ${ }^{[20]}$, predict pharmacokinetic and the effect of genetic polymorphisms of deferasirox ${ }^{[21]}$, and predict plasma concentration of febuxostat from different formulations ${ }^{[22]}$. Although we achieved good prediction results finally, both the stuck at the local minimum of BPANN and the variable selection trouble us a lot during the research process. In this study, the PCA and PSO were introduced into modeling and the final model of PSO-BPANN became more reliable and stable. What's more, the MIV of the gender and age were 127.56 and -150.14 which respect strong negative effects on the plasma concentration of omeprazole. The results of MIV are consistent with the conclusion that we found before. In addition, the MIV of body mass index and serum creatinine were 95.13 and -105.55 , respectively. We suspect that the positive effect of body mass index and the negative effect of serum creatinine should not been ignored, either.

Although the low number of subjects included in the study did not allow us to explore the effect of more variables on the pharmacokinetics of omeprazole enteric-coated tablets, such as the CYP genetic polymorphisms ${ }^{[23]}$. The model we established still had a good predictive effect on the plasma concentration of omeprazole in the Chinese population. We plan to introduce the effect of genetic polymorphisms into the PSO-BPANN in subsequent studies.

\section{Conclusions}

In this study, the effects of age and gender on pharmacokinetics study of omeprazole enteric-coated tablets in Chinese population were explored and a PSO-BPANN model was developed to predict the plasma concentration of omeprazole.

\section{Declarations}

\subsection{Ethics approval and consent to participate}

This clinical trial was approved by the Human Subject Research Ethics Committee. Written consent was obtained from all Subjects prior to enrollment. All methods were performed in accordance with the relevant guidelines and regulations by National Medical Products Administration. The Clinical trial registration numbers were CTR20170876 and the full date of registration was 04/AUG/2017.

\subsection{Consent for publication}

NOT APPLICABLE.

\subsection{Availability of data and materials}

All data and materials included in this study are available upon request by contact with the corresponding author.

\subsection{Competing interests}

The authors declare that they have no competing interests with respect to this work. 


\subsection{Funding}

This work was supported by the National Major Science and Technology projects of China (no. 2020ZX09201022).

\subsection{Authors' contributions}

BJ and ZRR conceived and designed the study. DDY and YH performed the experiments. YCX constructed the model and wrote the paper. JLC and HGL reviewed and edited the manuscript. All authors read and approved the manuscript.

\subsection{Acknowledgments}

All authors would like to thank participating subjects and to acknowledge all clinical center personnel who contributed to this study.

\section{References}

1. R.T. Kavitt, A.M. Lipowska, A. Anyane-Yeboa, I.M. Gralnek, Diagnosis and Treatment of Peptic Ulcer Disease, The American journal of medicine, 132 (2019) 447-456.

2. K.T. Chung, V.G. Shelat, Perforated peptic ulcer - an update, World journal of gastrointestinal surgery, 9 (2017) $1-12$.

3. J. Abbasi, Barry Marshall, MD: H pylori 35 Years Later, Jama, 317 (2017) 1400-1402.

4. B.A. van Hout, R.M. Klok, J.R. Brouwers, M.J. Postma, A pharmacoeconomic comparison of the efficacy and costs of pantoprazole and omeprazole for the treatment of peptic ulcer or gastroesophageal reflux disease in The Netherlands, Clinical therapeutics, 25 (2003) 635-646.

5. M.N. Abed, F.A. Alassaf, M.H.M. Jasim, M. Alfahad, M.E. Qazzaz, Comparison of Antioxidant Effects of the Proton Pump-Inhibiting Drugs Omeprazole, Esomeprazole, Lansoprazole, Pantoprazole, and Rabeprazole, Pharmacology, (2020) 1-7.

6. S. Karami, G. Dehghanzadeh, M. Haghighat, R. Mirzaei, H.R. Rahimi, Pharmacokinetic Comparison of Omeprazole Granule and Suspension Forms in Children: A Randomized, Parallel Pilot Trial, Drug research, 66 (2016) 165-168.

7. A. Zarghi, S.M. Foroutan, A. Shafaati, A. Khoddam, HPLC determination of omeprazole in human plasma using a monolithic column, Arzneimittel-Forschung, 56 (2006) 382-386.

8. U. Hofmann, M. Schwab, G. Treiber, U. Klotz, Sensitive quantification of omeprazole and its metabolites in human plasma by liquid chromatography-mass spectrometry, Journal of chromatography. B, Analytical technologies in the biomedical and life sciences, 831 (2006) 85-90.

9. M. Vaz-da-Silva, A.I. Loureiro, T. Nunes, J. Maia, S. Tavares, A. Falcão, P. Silveira, L. Almeida, P. Soares-da-Silva, Bioavailability and bioequivalence of two enteric-coated formulations of omeprazole in fasting and fed conditions, Clinical drug investigation, 25 (2005) 391-399.

10. A. Kaur, M. Kaur, A Review of Parameters for Improving the Performance of Particle Swarm Optimization, International Journal of Hybrid Information Technology, 8 (2015) 7-14.

11. F. Vandenbergh, A. Engelbrecht, A study of particle swarm optimization particle trajectories, Information Sciences, 176 (2006) 937-971. 
12. N.K. Jain, U. Nangia, J. Jain, A Review of Particle Swarm Optimization, Journal of The Institution of Engineers (India): Series B, 99 (2018) 407-411.

13. F.H. Zhou, Z.Z. Liao, A Particle Swarm Optimization Algorithm, Applied Mechanics and Materials, 303-306 (2013) 1369-1372.

14. E. Bal Beşikçi, O. Arslan, O. Turan, A.I. Ölçer, An artificial neural network based decision support system for energy efficient ship operations, Computers \& Operations Research, 66 (2016) 393-401.

15. K. Thishya, K.K. Vattam, S.M. Naushad, S.B. Raju, V.K. Kutala, Artificial neural network model for predicting the bioavailability of tacrolimus in patients with renal transplantation, PloS one, 13 (2018) e0191921.

16. T. Kalman Šipoš, I. Miličević, R. Siddique, Model for mix design of brick aggregate concrete based on neural network modelling, Construction and Building Materials, 148 (2017) 757-769.

17. A. Lee, Z. Geem, K.-D. Suh, Determination of Optimal Initial Weights of an Artificial Neural Network by Using the Harmony Search Algorithm: Application to Breakwater Armor Stones, Applied Sciences, 6 (2016) 164.

18. J.-R. Zhang, J. Zhang, T.-M. Lok, M.R. Lyu, A hybrid particle swarm optimization-back-propagation algorithm for feedforward neural network training, Applied Mathematics and Computation, 185 (2007) 1026-1037.

19. Y.-T. Chang, J. Lin, J.-S. Shieh, M.F. Abbod, Optimization the Initial Weights of Artificial Neural Networks via Genetic Algorithm Applied to Hip Bone Fracture Prediction, Advances in Fuzzy Systems, 2012 (2012) 1-9.

20. Y. Xu, H. Lou, J. Chen, B. Jiang, D. Yang, Y. Hu, Z. Ruan, Application of a Backpropagation Artificial Neural Network in Predicting Plasma Concentration and Pharmacokinetic Parameters of Oral Single-Dose Rosuvastatin in Healthy Subjects, Clinical pharmacology in drug development, 9 (2020) 867-875.

21. J. Chen, Y. Xu, H. Lou, B. Jiang, R. Shao, D. Yang, Y. Hu, Z. Ruan, Effect of Genetic Polymorphisms on the Pharmacokinetics of Deferasirox in Healthy Chinese Subjects and an Artificial Neural Networks Model for Pharmacokinetic Prediction, European journal of drug metabolism and pharmacokinetics, (2020).

22. Y. Xu, J. Chen, D. Yang, Y. Hu, X. Hu, B. Jiang, Z. Ruan, H. Lou, Development of LC-MS/MS determination method and backpropagation artificial neural networks pharmacokinetic model of febuxostat in healthy subjects, Journal of Clinical Pharmacy and Therapeutics, $n / a$.

23. M. Koukoula, Y. Dotsikas, E. Molou, K.H. Schulpis, G. Thodi, M. Chatzidaki, O. Triantafylli, Y.L. Loukas, Study of the effect of CYP2C19 polymorphisms on omeprazole pharmacokinetics by utilizing validated LC-MS/MS and Real Time-PCR methods, Journal of chromatography. B, Analytical technologies in the biomedical and life sciences, 1047 (2017) 173-179.

\section{Figures}




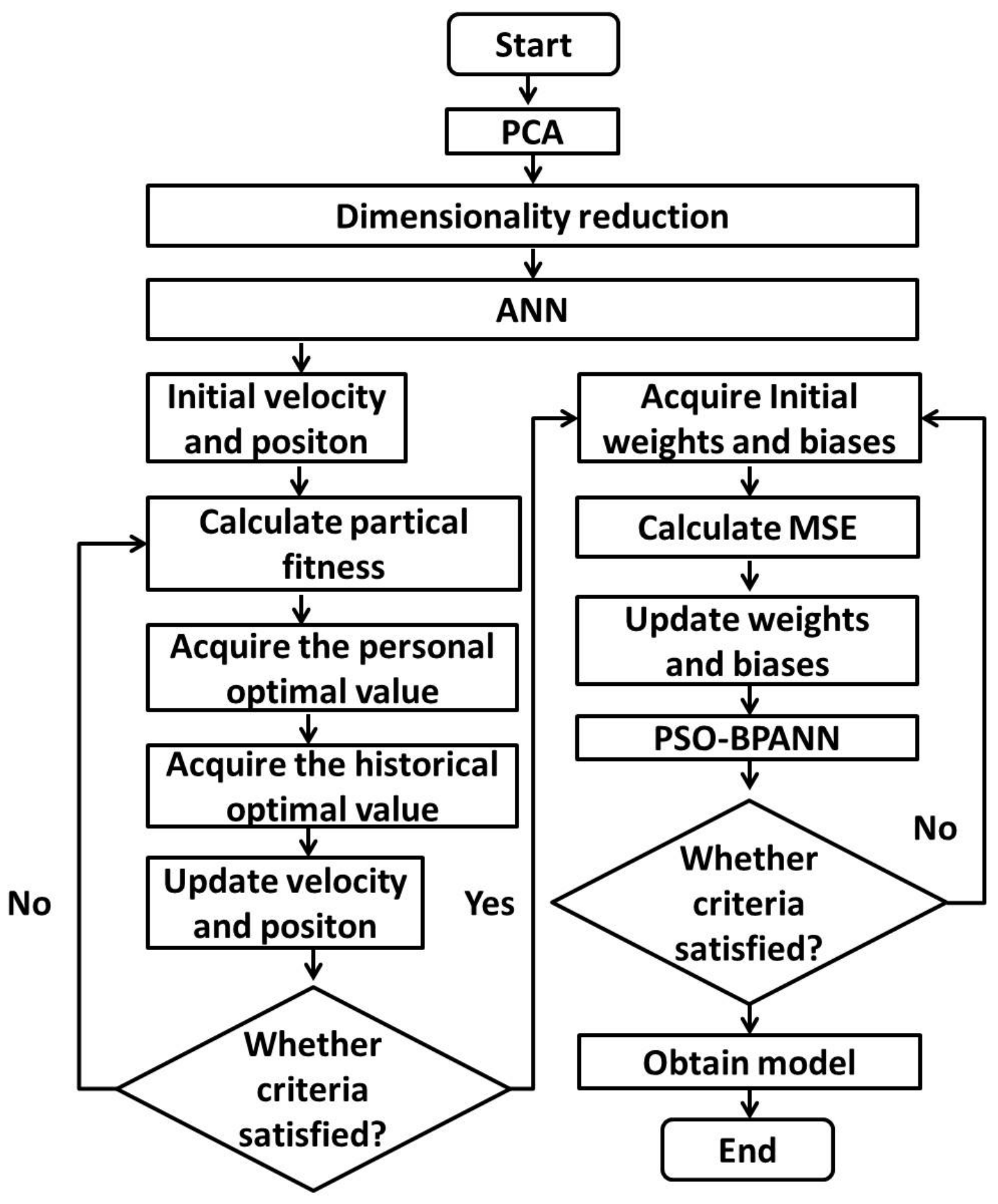

Figure 1

The overall calculation process 

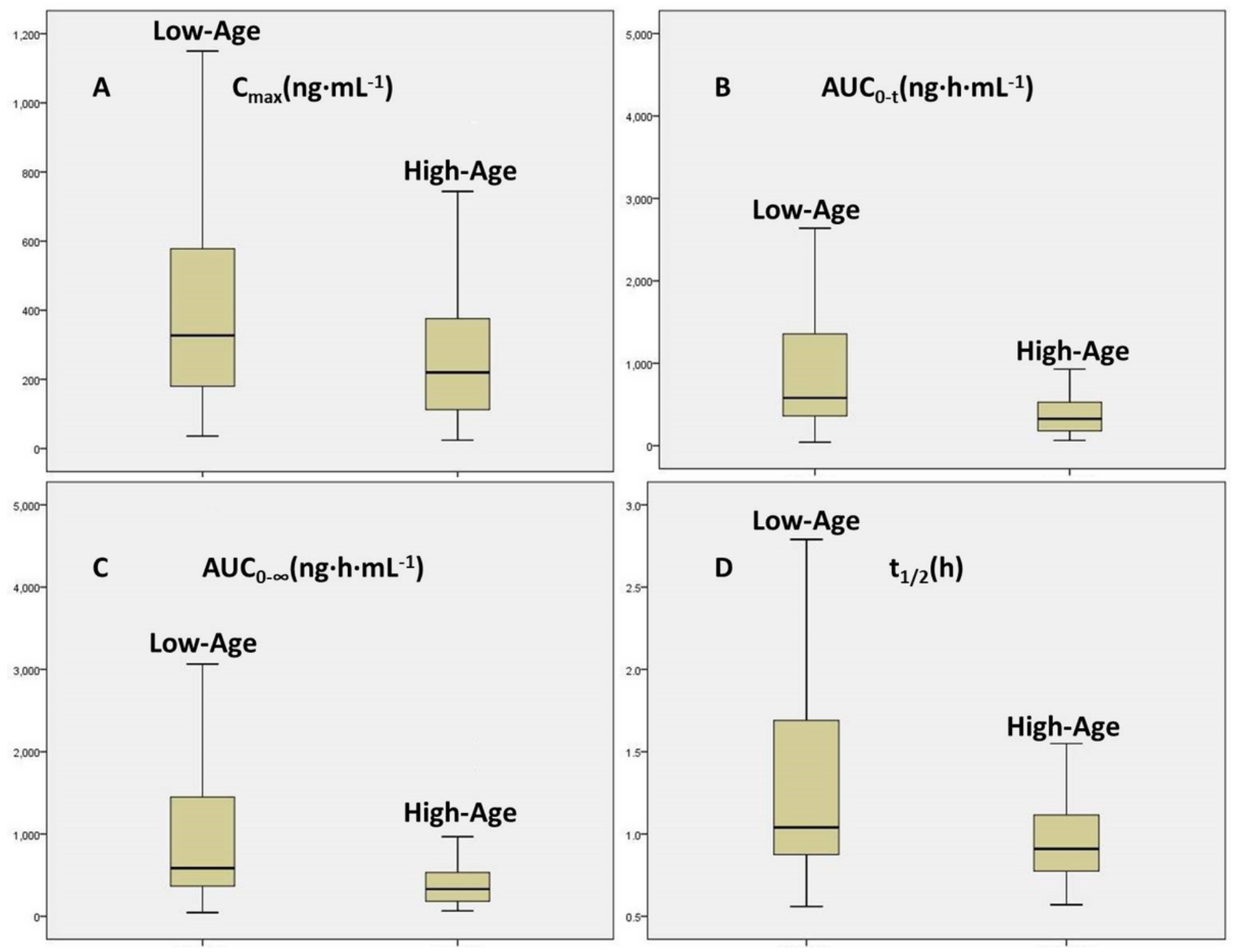

Figure 2

Cmax, AUC0-t, AUC0- $\infty$ and t1/2 values have significant differences when omeprazole was administered by low-age groups or high-age groups 

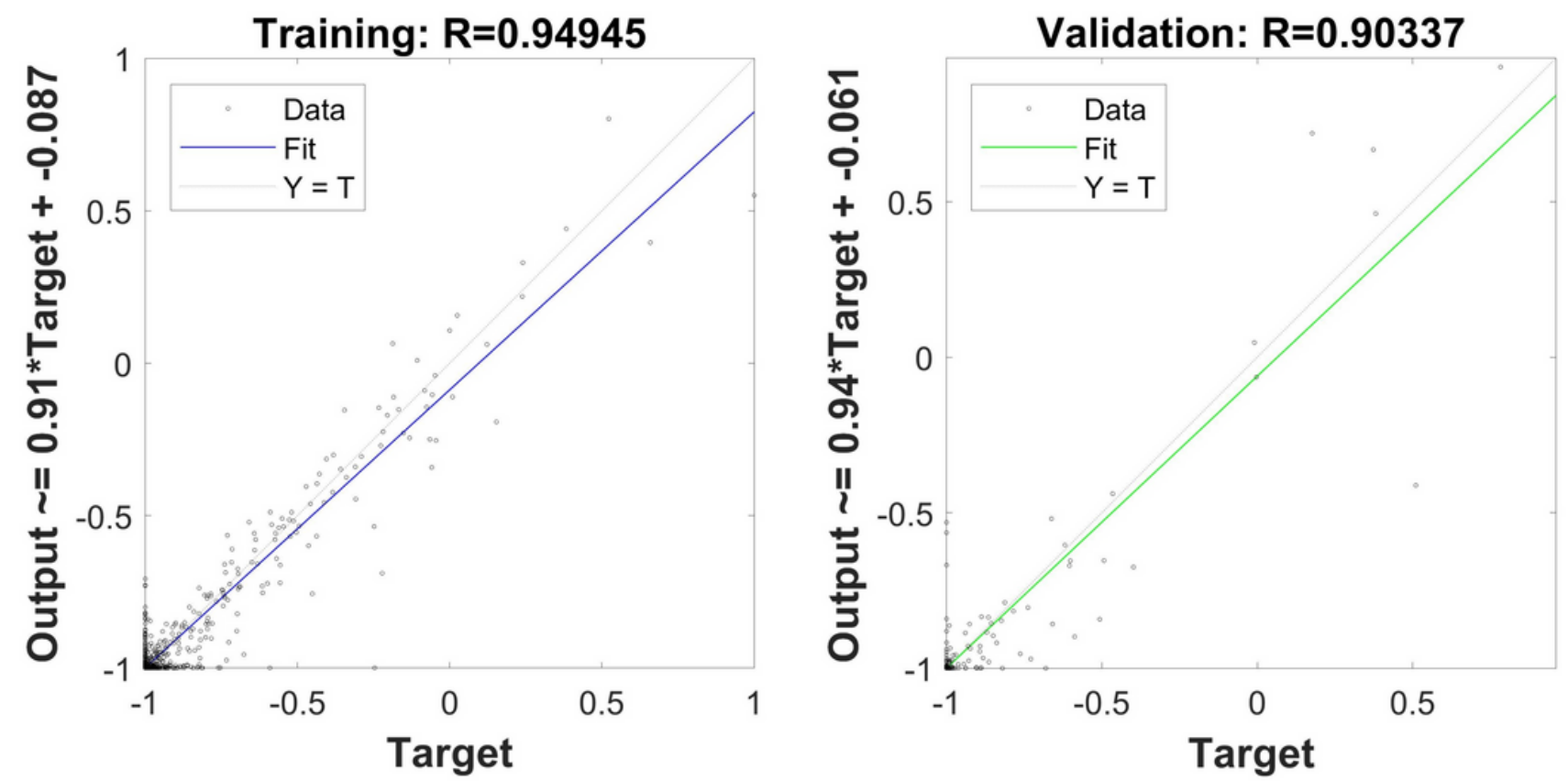

Figure 3

The correlation coefficient of training and validation 


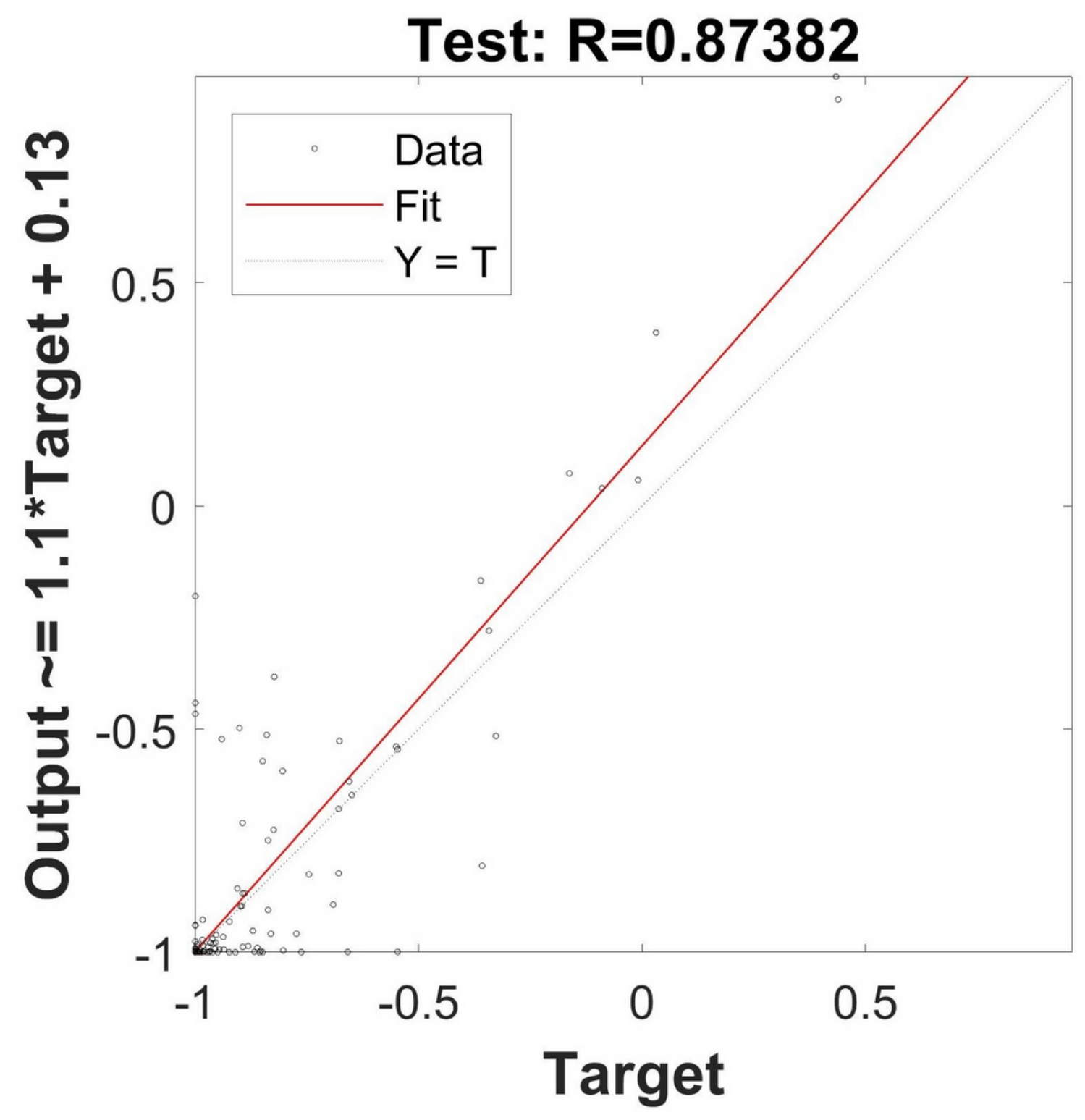

Figure 4

The results of predict values compared with measured values were shown in Fig 4 and the correlation coefficient was calculated. 